EGU2020-9322

https://doi.org/10.5194/egusphere-egu2020-9322

EGU General Assembly 2020

(c) Author(s) 2020. This work is distributed under

the Creative Commons Attribution 4.0 License.

\title{
Quantitative reconstruction of Holocene vegetation cover in Flanders, Belgium - a study based on pollen-records from alluvial floodplains
}

Renske Hoevers, Nils Broothaerts, and Gert Verstraeten

KU Leuven, Department of Earth and Environmental Sciences, Leuven, Belgium (renske.hoevers@kuleuven.be)

Rivers and alluvial floodplains are dynamic environments facing natural and anthropogenic impacts. A thorough knowledge of the functioning of alluvial floodplains and their sensitivity to changes in internal and external driving forces is required for sustainable management of these ecosystems.

During the Early and Middle Holocene, most floodplains in northern and central Belgium were stable environments with limited floodplain aggradation resulting in the formation of peat. During these times, floodplains consisted mainly of large marshes where peat accumulated and river channels were absent or small. During the Late Holocene, these environments changed completely towards single channel meandering rivers with overbank deposits, impeding peat accumulation, largely as a result of increasing anthropogenic impact. However, this evolution in floodplain geoecology is diachronous as some river valleys transform a few thousand years before others.

Previous research already showed that river systems respond non-linearly to changes in land-use and land-cover in their catchments, as land-use intensity and slope-channel coupling need to cross a certain threshold to result in significant change. Hence, the differences in timing of floodplain response can to some extent be related to different land-use trajectories in the river catchments. Based on previous qualitative and semi-quantitative research the exact land-cover threshold, i.e. the land-use intensity required to result in transformation of the fluvial system, as well as the timing at which this threshold is crossed, could not be detected. Hence, a quantitative assessment of the resilience of floodplain environments to regional land-use changes is needed. A successful pilot REVEALS-based reconstruction of the Dijle catchment, showed a decrease in forest cover from the Bronze Age onwards, accompanied by an increase in the proportion of cereals.

In this study, we constructed a database of pollen-records collected in the eastern part of Flanders, mainly retrieved from river floodplains, as deposits from large lakes are not available in the area. We selected sites with varying soil properties, topographies, and histories of human impact in their catchments, to uncover regional differences in land-cover evolution through the application of the REVEALS model. To assess the applicability of this model to alluvial deposits, modern pollen data will be included and outcomes will be compared to modern vegetation maps. 
In addition, vegetation reconstructions will be compared with historical maps (available from 1778 AD onwards).

Results will help to answer questions regarding the sensitivity of Flanders to (future) environmental changes. Our study contributes to the understanding of Holocene land-cover change and its drivers, by providing quantitative vegetation cover reconstructions for Belgium that are currently lacking in the European REVEALS reconstructions. Moreover, it extends the application of the REVEALS model to pollen-records retrieved from alluvial deposits. 